\title{
Characterization of raw materials based on supply risk indicators for Europe
}

\author{
Lucia Mancini $^{1} \cdot$ Lorenzo Benini $^{1} \cdot$ Serenella Sala $^{1}$
}

Received: 14 July 2015 / Accepted: 20 May 2016 / Published online: 2 June 2016

(C) The Author(s) 2016. This article is published with open access at Springerlink.com

\begin{abstract}
Purpose The concept of "resource criticality" has recently emerged as a policy priority and research subject, usually referred to the risk of supply disruption for mineral resources, due to economic and geopolitical reasons. Different methodologies for assessing critical raw materials (CRM) have been developed in governmental and research contexts, and the possibility of including the resource security aspect in life cycle assessment (LCA) has been claimed by different authors. The present paper aims at integrating CRM considerations in LCA in order to address socio-economic and strategic aspects related to resource use.

Methods In this paper, we first explore how resource criticality could be interpreted, taking into account a wider perspective and a multidimensional concept. This includes the consideration of environmental and depletion aspects, in addition to the dominant interpretation, based on economic and geopolitical considerations. We then focus on the economic dimension of the resource criticality and propose the integration of this aspect in LCA through the use of characterization factors (CFs) based on the supply risk factors for Europe. Four different methodological options for resource security CFs are tested in the impact assessment of 50 processes and products.
\end{abstract}

Responsible editor: Alessandra Zamagni

Electronic supplementary material The online version of this article (doi:10.1007/s11367-016-1137-2) contains supplementary material, which is available to authorized users.

Serenella Sala

Serenella.sala@jrc.ec.europa.eu

1 European Commission, Joint Research Centre, Institute for Environment and Sustainability, Sustainability Assessment Unit, Via Enrico Fermi 2749; T.P. 290, 21027 Ispra, VA, Italy
These options include the following: supply risk factors as such; two exponential functions of the supply risk factors, aimed at increasing the variability of the dataset, and the ratio between supply risk and production data, which reflect the size of the market, giving more importance to the materials used in small amounts in products and applications (like, e.g. specialty metals, that are often perceived as critical).

Results and discussion The results show how the impact depends on the supply risk factors or on the mass depending on the algorithm used. Even if there is no objective way to establish how much importance should be given to one aspect or the other, we conclude that the use of the factors "supply risk/ production" results might better reflect CRM importance and therefore could be used in LCA for an assessment of resource security impact for EU. Applying an exponent to the supply risk factors, the values are spread on a wider range and it is possible to spot the CRM among the resources within an inventory.

Conclusions The choice of the indicator is based rather on how important is the need of identifying a CRM in the inventory, e.g. in order to optimize CRM use, explore substitution options and enhance recovery in waste management.

Keywords Critical raw materials - Characterization factors · Life cycle assessment · Resource impact assessment · Supply risk

\section{Introduction}

The security of supply of mineral raw materials has become a high-priority theme in the political agenda of many countries, especially those highly dependent on imports. At EU level, resource security is claimed as a policy objective both in the Raw Materials Initiative (EC-European Commission 2008) 
and within the resource efficiency policy (EC-European Commission 2011a). "Criticality" has also emerged as a research subject, and different studies and methodologies for assessing critical raw materials (CRMs) have been developed (e.g. CCMI CER and NRC 2008; AEA Technology 2010; EC-European Commission 2010; Erdmann and Graedel 2011; Graedel et al. 2012; BGS 2012; Achzet and Helbig 2013). Most of them are based on supply risk and vulnerability of a system to a potential supply disruption. Security of supply is also one of the conditions for ensuring a sustainable supply of raw materials from an economic point of view. It is debated if environmental life cycle assessment (LCA) (ISO 14044 2006) should take into account resource security, as well as other socio-economic issues related to resources or if these aspects should be included in a social LCA (Klinglmaier et al. 2013; Mancini et al. 2015; 2013). Recent works proposed the integration of resource criticality assessment within the life cycle sustainability assessment (LCSA) framework (Gemechu et al. 2016; 2015; Schneider et al. 2014; Sonnemann et al. 2015).

Resource security is a recurrent issue over history, mainly determined by the uneven geographical distribution of mineral reserves around the globe and the consequent import dependency in resource-poor countries (Buijs et al. 2012; Glöser et al. 2015). In addition to the uneven geographical distribution of mines, economic development policies set by developed countries have contributed in setting the scene of criticality. For example, several European countries have been exploiting post-colonial economic relationships for the supply of raw materials, closing domestic mines having lower value added and incentivizing domestically manufacturing and service sectors.

The concern about resource security has recently regained importance. Global population growth, new consumption habits, technological change and economic development of some countries have enlarged the demand for raw materials both in terms of amount and variety of materials used. Some metals are increasingly relevant for emerging technologies, including those that are supposed to contribute to more sustainable societies, e.g. low carbon energy supply and transportation technologies (Buchert et al. 2009; Nansai et al. 2015). For instance, rare earths (REE) are needed for automotive catalysts or fluorescent lamps that are used in hybrid cars and wind turbines; "platinum group metals" (PGM) are used in many new technologies, including fuel cells for electric vehicles; silicon metal is a key component of photovoltaic panels.

Supply of raw materials can be threatened by different factors: geological, technological, geo-political, economic, environmental and social. In the criticality assessments, the aspects that are commonly included are related to the raw material markets and economy (e.g. market concentration, consumption and demand), technology (e.g. recycling potential, substitutability, by-products, etc.) and geo-political concerns (governance and political stability of producing countries). Biophysical availability of raw materials is also included in some assessments (Erdmann and Graedel 2011; Graedel et al. 2012; Morley and Eatherley 2008), while in others, this aspect is not addressed due to the short time frame of the study, e.g. in the assessment of CRMs for the European economy by the European Commission (EC) $(2014$; 2010). Systematic reviews of existing methodologies for criticality assessment have been compiled by Erdmann and Graedel (2011) (until 2010) and Sonnemann et al. (2015) (for the period 2010 2015).

While resource security refers to the access to resources for economic and geo-political reasons, resource availability for present and future generations is a central issue in the sustainability discourse and concerns the geological and physical occurrence of a resource in the Earth, together with technological capability of extracting it. In LCA, natural resources represent one of the areas of protection (next to natural environment and human health). The impact related to resource use is assessed through different methods in which limitations to the accessibility due to geopolitical reasons are usually not taken into account. The need of taking into account in LCA the economic and geopolitical aspects that can reduce resource availability has been acknowledged (Mancini et al. 2015; Schneider et al. 2014; Sonnemann et al. 2015) and some methods have been proposed in this context.

Schneider et al. (2014) develop a set of impact categories for modelling the economic dimension of resource provision capability within the LCA framework and calculate the aggregate indicator economic scarcity potential (ESP) for 17 metals. Sonnemann et al. (2015) propose to integrate criticality considerations under LCSA framework for having a more meaningful assessment of the impacts in the area of protection natural resources. Following this conceptual framework, Gemechu et al. (2016) propose a method of calculation for the geopolitical supply risk of resources, imported in different countries. The resulting characterization factors (CFs) (covering 14 resources and 12 importing countries, plus the EU) are applied in a case study on the LCA of electric vehicles, complementing the environmental impact assessment with geopolitical supply risk (Gemechu et al. 2015). The present work introduces an additional method for the integration of resource criticality considerations in LCA, using supply risk factors published by the EC $(2014 ; 2010)$ as CFs in the impact assessment phase of LCA and presenting different options for their implementation at EU level. With respect to other methods, this proposal builds on an existing publicly available database, having a wide, updated and transparently documented set of information on resources' security of supply (actually 54 materials, including also some biotic). This dataset, which is foreseen to be updated every 3 years, gathers ready-to-use information on raw materials that could be applied in life cycle 
impact assessment with limited effort, capitalizing on the work fulfilled by the EC on criticality.

The application of supply risk scores in LCA is intended to support industry and policy decision making in analyzing supply chains from a resource security perspective, warning on potential risk for the economic availability of material resources along the supply chains.

The scope of this paper is twofold: first, it discusses the nature of the resource criticality concept, beyond the current mainstream economic and geopolitical interpretation, by highlighting the multiple perspectives of resource criticality that could be embraced within a sustainability study (Sect. 2). Secondly, it focuses on the socio-economic and geopolitical perspective and proposes the implementation of CFs at EU level based on supply risk factors (Sect. 3). Different methodological options for calculating characterization factors are tested on life cycle inventories (LCI) of several products retrieved from Ecoinvent, and results are discussed using an illustrative product (computer laptop) in Sect. 4. The concluding considerations on the feasibility of the inclusion of socio-economic aspects in LCA and on the choice between different methodological options are presented in Sect. 5.

\section{What is resource criticality? From the criticality matrix to a multidimensional concept}

The dominant definition and political interpretation of the resource criticality concept focus on economic aspects and supply risk related to raw materials. A common tool for the assessment and communication of the resource criticality in both research and policy contexts is the "criticality matrix", composed of two dimensions: supply risk (or risk of supply disruption) and economic importance (or vulnerability of the system to a supply disruption) (Erdmann and Graedel 2011; Glöser et al. 2015; Knoeri et al. 2013). In the case of Graedel et al. (2012), a third dimension is added, in order to take environmental implications into account. As outlined by Glöser et al. (2015), this representation is a modification of the classical risk matrix, which combines the potential damage and the probability of occurrence of an event. Other approaches on criticality assessment quantify a single risk index (e.g. Morley and Eatherley 2008) or a mining risk footprint indicator (Nansai et al. 2015) and use scenario analysis, time series analysis or agent-based behaviour model in order to forecast demand and supply side developments (e.g. Frondel et al. 2005; Knoeri et al. 2013).

A harmonized and standard definition of criticality does not exist; in fact, criticality is a relative concept and the relevant dimensions can (and should) be defined by the user according to his/her particular needs (Tercero Espinoza 2013). In the EC study on resource criticality (EC-European Commission 2014), a CRM is defined as a raw material for which "the risks of supply shortage and their impacts on the economy are higher than for most of the other raw materials". A similar interpretation is given in Buijs et al. (2012), while other definitions stress the lack of substitution and the consequent reduced availability or price rise in key applications as main feature of CRMs (CCMI CER and NRC 2008). In Graedel et al. (2012), supply risk is assessed for different temporal perspectives (medium and long term) and the vulnerability to supply restrictions is specified at corporate, national and global level.

Most of the studies on resource criticality focus on abiotic raw materials or on metals only. Instead, the methodology published by the EC (2014) has included some biotic raw materials in the last assessment (e.g. wood and natural rubber), within the subset of non-agricultural and non-energy materials. The level of the analysis varies in the methodology proposed by Graedel (from corporate, national and global) (Graedel et al. 2012), while it usually refers to an economic sector or the national economy as a whole in the other studies.

The EC methodology takes into account the role of materials in the EU economy, focusing on the EU industrial sector; the publication of the CRM list aims at setting priorities in policy making focusing efforts where the major risks are foreseen, as well as raising awareness on the importance of raw materials. Two variables are taken into account in this methodology: economic importance (EI) and supply risk due to poor governance $\left(\mathrm{SR}_{\mathrm{WGI}}\right)$. The latter encompasses four subcomponents:

1. Level of concentration of worldwide production of raw materials (using the Herfindahl-Hirschman Index (HHI), which accounts for market competitiveness)

2. Political and economic stability of the producing countries (using the Worldwide Governance Indicator, which considers four aspects of governance: voice and accountability, political stability and absence of violence/terrorism, government effectiveness, regulatory quality, rule of law and control of corruption)

3. Potential of substitution of raw materials (based on a substitutability index estimated through experts' opinion and aggregating the substitutability for the different uses)

4. Recycling rate (using estimates from a UNEP report on end-of-life recycling rates, UNEP 2011)

The supply risk based on environmental country risk $\left(\mathrm{SR}_{\mathrm{EPI}}\right)$ was initially included in the assessment, but in the last update, it was not considered relevant enough and only the $\mathrm{SR}_{\mathrm{WGI}}$ was taken into account. Currently, the identification of CRMs is performed by means of thresholds setting. Therefore, a threshold is set for each of the two variables which characterize any raw material (EI and $\mathrm{SR}_{\mathrm{WGI}}$ ), and the combination of the two leads to the definition of the "criticality area". If a raw material is characterized by values of EI and $\mathrm{SR}_{\mathrm{WGI}}$ higher than the 
thresholds, it is then to be considered as critical. The 2014 study reports figures on $\mathrm{EI}$ and $\mathrm{SR}_{\mathrm{WGI}}$ (and sub-indicators contained in each variable) for 54 non-energy, non-agricultural materials (EC-European Commission 2014).

In spite of the dominant interpretation of resource criticality (focusing on economic and geo-political aspects), this concept can be interpreted in a much wider manner. The interplay of environmental, as well as socio-economic aspects, is still the fundamental basis of any discourse on resource efficiency and on sustainable use of resources, being abiotic or biotic due to their functional value for society (de Haes et al. 1999). As suggested by some authors (e.g. Bleischwitz et al. 2012; Prins et al. 2011), criticality is a multidimensional concept, including both the environmental dimension (e.g. aspects like recyclability, overuse of ecosystems, environmental pressures on ecosystems), the economic dimension (e.g. concentration of supply, import dependency, etc.) and the socio-political dimension (e.g. human rights violations, resource conflicts, illicit trade, precarious working conditions). According to this wider interpretation, a resource can be critical for different reasons: e.g. because it is indispensable for the agricultural production (e.g. phosphorus), because it is strictly linked to regional conflicts and illicitly traded (e.g. coltan/tantalum), because of the strong reliance on imports (e.g. rare earths), because it is difficult to substitute at present (e.g. PGM) or because it is indispensable for all energy infrastructure (e.g. copper). Therefore, the challenges related to natural resources can have a different nature, and the stakeholders/actors affected by a potential supply restriction can differ from enterprises, to consumers, local communities, etc. Table 1 illustrates a list of critical factors that can be applied to the use of resources and the coverage of these aspects in indicators used in life cycle impact assessment (LCIA) (both in social and environmental LCA) and in two criticality methodologies. Both complementarities and overlapping exist between the two assessment frameworks. In particular, some aspects in the socio-political and economic dimensions are assessed both in criticality assessment and in SLCA, while, when considering ELCA alone, criticality assessment can complement the resource assessment with additional aspects. Some environmental aspects (potential ecosystem deprivation and overuse of ecosystems) and social aspects (illicit trade and imbalance of power) are not included in any assessment framework and represent current research gaps. It is also evident that ELCA (blue area in the table) has a limited assessment capacity with regard to natural resources. As we consider resource depletion more an economic rather than an environmental problem, most of the environmental critical factors are not considered in ELCA. Concerning the social and economic aspects, ELCA could be complemented by criticality assessment, or by SLCA, which includes a wide set of indicators.

Criticality, indeed, is not an absolute concept and the methodologies for the assessment of CRMs have to implicitly answer the question: "critical to whom?" (Sala 2013). Most of the methodologies look at the economies or even at certain industrial sectors; instead, a socio-ecological perspective on resource criticality would produce very different results. The Maslow pyramid of human needs (Maslow 1943), for instance, offers a hierarchy that underlies the importance of satisfying lower-order needs before addressing the higher-order needs. ${ }^{1}$ As shown in Fig. 1, adopting such framework for the prioritization of resources and the identification of the critical ones would drastically change the result of current CRM lists, having many specialty metals for high-tech applications identified as critical.

\section{Methodology for characterization of supply risk in life cycle impact assessment}

Even though SLCA is devoted to the assessment of social and socio-economic aspects of products along the supply chain, we argue that criticality aspects would be better gathered in (environmental) LCA, since it uses biophysical elementary flows (e.g. mass unit) in the compilation of the inventory. As shown in Fig. 2, LCA takes into account a wide range of impacts that are not environmental only: e.g. those on human health and on natural resources. We would therefore define LCA as a methodology assessing the impacts (of environmental, economic or social nature) due to environmental interventions along a supply chain, i.e. due to the extraction or emission of physical substances, while social LCA and life cycle costing base their assessment on non-environmental flow exchange (e.g. value and working hours).

In LCIA, the input/output elementary flows compiled in the inventory of materials and emissions are quantified in terms of indicators through characterization factors (CFs). An emission or resource flow is multiplied by its respective $\mathrm{CF}$ and contributes to an indicator of impact, which consists of the sum of all contributions originating from the different input and output flows, within a given category. The nature of the indicators is multiple, some reflecting contributions to

\footnotetext{
${ }^{1}$ The psychologist Abraham Maslow conceived a hierarchy of five levels of human needs, arranged into the format of a pyramid (as in Fig. 1). He hypothesized that until the lowest levels of needs had been fulfilled, individuals could not deal with higher levels of needs. Maslow's model has been studied in various disciplines, including business (as a model for understanding motivation), in the social sciences (used as a model for understanding the needs of individuals) (Benson and Dundis 2003), in ecology (e.g., to explain how ecosystem services relate to human needs (Dominati et al. 2010)), and in environmental science (e.g., in the context of water resources management, offering an approach for the planning of sustainable water systems (Melloul and Collin 2003)).
} 
Table 1 Resource criticality as a multidimensional concept

\begin{tabular}{|c|c|c|c|c|}
\hline \multirow{16}{*}{ 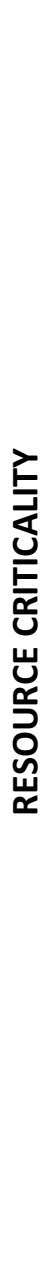 } & & Critical factors & Coverage in LCA indicators & $\begin{array}{l}\text { Coverage in criticality } \\
\text { methodologies }(a, b)\end{array}$ \\
\hline & \multirow{4}{*}{ 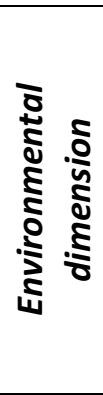 } & $\begin{array}{l}\text { Concentration of extraction } \\
\text { and environmental pressures }\end{array}$ & & in Environmental Implications (b) \\
\hline & & Recyclability & $\begin{array}{l}\text { Anthropogenic stock extended } \\
\text { Abiotic Depletion Potential } \\
\text { (ELCA) (partially captured) }\end{array}$ & in Supply Risk $\left(a, b^{(1)}\right)$ \\
\hline & & $\begin{array}{l}\text { Potential ecosystem deprivation } \\
\text { (Competition of resources between } \\
\text { human needs and ecosystems) }\end{array}$ & - & - \\
\hline & & $\begin{array}{l}\text { Overuse of ecosystems (above their } \\
\text { carrying capacity) }\end{array}$ & - & - \\
\hline & \multirow{5}{*}{ 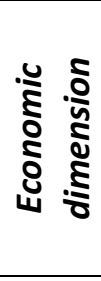 } & Depletion of reserves & Abiotic Depletion Potential (ELCA) & in Depletion time (b) \\
\hline & & Import-dependency & & $\begin{array}{l}\text { in Vulnerability to Supply } \\
\text { Restrictions (b) }\end{array}$ \\
\hline & & Lifecycle wide material losses & & in Supply Risk $\left(b^{(2)}\right)$ \\
\hline & & Concentration of production & set of indicators in $\operatorname{SLCA}^{(3)}$ & $\begin{array}{l}\text { Herfindahl-Hirschman Index (HHI) } \\
\text { in Supply Risk }(\mathrm{a}, \mathrm{b})\end{array}$ \\
\hline & & Substitutability & & in Supply Risk $(a, b)$ \\
\hline & \multirow{6}{*}{ 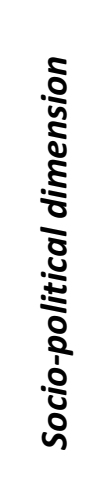 } & $\begin{array}{l}\text { Human rights violations / } \\
\text { Child labour }\end{array}$ & set of indicators in SLCA $(4)$ & \\
\hline & & $\begin{array}{l}\text { Precarious and dangerous } \\
\text { working conditions }\end{array}$ & set of indicators in SLCA $(5)$ & \\
\hline & & Illicit trade & - & - \\
\hline & & Imbalances of power & - & - \\
\hline & & $\begin{array}{l}\text { Governance and institutional } \\
\text { setting }\end{array}$ & set of indicators in SLCA ${ }^{(6)}$ & $\begin{array}{l}\text { in Supply Risk: Policy Potential } \\
\text { Index (b), Human Development } \\
\text { Index (b), Worldwide Governance } \\
\text { Indicator (a, b) }\end{array}$ \\
\hline & & $\begin{array}{l}\text { (Potential) resource conflicts and } \\
\text { competition between different } \\
\text { resource uses }\end{array}$ & in $\operatorname{SLCA}{ }^{(7)}$ & \\
\hline
\end{tabular}

Resource criticality as a multidimensional concept: coverage of critical factors in existing indicators used in the life cycle assessment framework (environmental and social LCA) and in two criticality assessment methodologies (a: EU methodology for Critical Raw Materials, 2013; b: methodology for criticality assessment by Graedel et al. 2012). Own elaboration based on Bleischwitz et al. 2012. Indicators in SLCA refer to the list of indicators in the Product Social Impact Life Cycle Assessment (PSILCA) database (Sala et al. 2015) - : not covered in existing methodologies; (1) included in the calculation of depletion time; (2) included in the calculation of depletion time as "net loss to tailings, slag and from other processes" ;(3) under "fair competition" category: presence of anti-competitive behaviour or violation of anti-trust and monopoly legislation and presence of policies to prevent anti-competitive behaviour; (4) under the subcategory "child labour"; (5) under the subcategories "forced labour" and "health and safety"; (6) under the subcategory "corruption"; and (7) indicator: description of potential material resource conflicts under the subcategory "access to material resources"

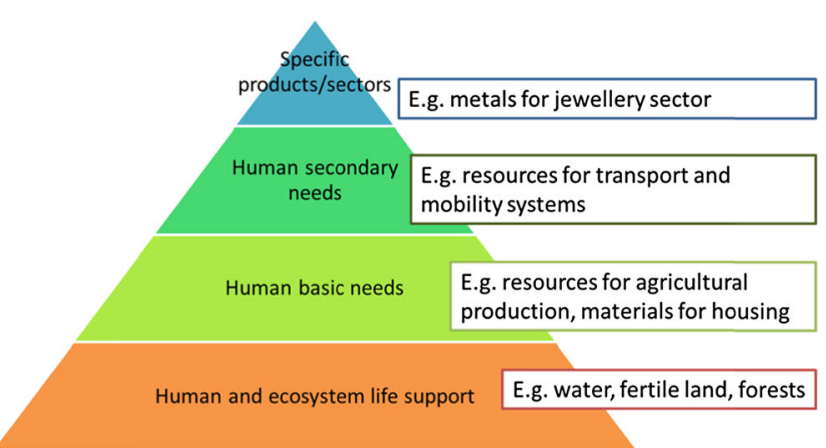

Fig. 1 An example of resource prioritization based on the adaptation of the Maslow pyramid of human needs impacts, risks or pressures and some reflecting environment, health and/or socio-economic considerations.

LC inventories could be readily used to analyze the use of CRM along the life cycle, relying on the outcomes of policyor business-driven CRM assessments, in order to characterize their relevance. At the impact assessment level, indicators used for the assessment of criticality can be applied to develop $\mathrm{CFs}$, which would reflect the socio-economic and geopolitical perspective. As outlined in Mancini et al. (2013), the main methodological hurdles and inconsistencies that have to be faced in this operation consist of the following: (i) the "relativity" of the criticality assessment (generally referred to a subject, a geographical region, a timeframe); (ii) the presence of elements of subjectivity (i.e. thresholds are set to establish which materials are critical); (iii) the temporary nature of the 


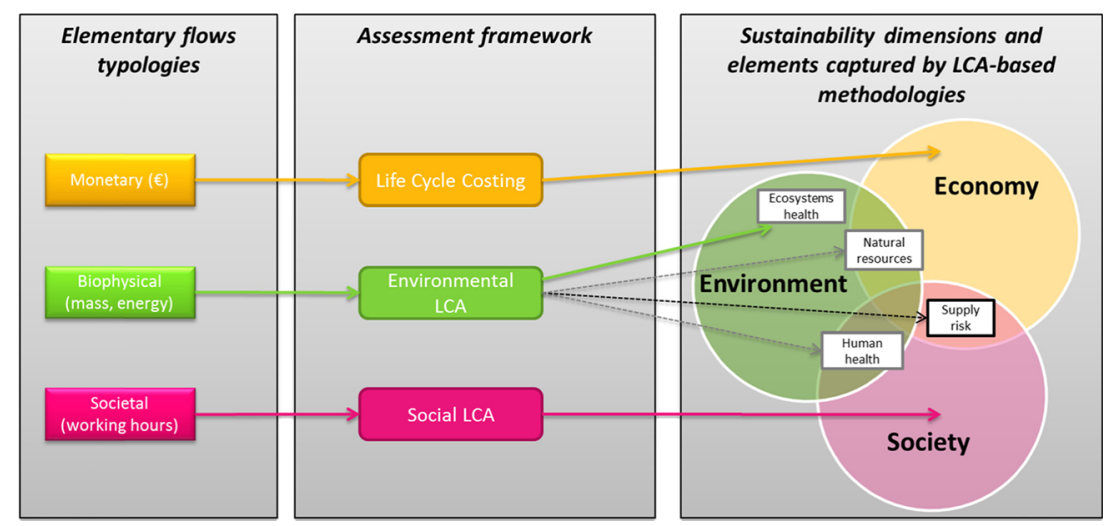

Fig. 2 Different typologies of elementary flows characterize life cyclebased methodologies, namely monetary flows in LCC, biophysical flows in ELCA and labour-related flows in social LCA. However, despite being linked to the calculation framework of ELCA, biophysical flows may lead to calculation of impacts not only in the sustainability dimension

assessments (the condition of criticality can quickly change over time, even in the short run), which connotes a strategic assessment. Moreover, in the criticality methodology, the materials' substitution potential was estimated by a group of experts: the lack of a quantitative and transparent methodology for the calculation of the substitution index represents a source of uncertainty in the impact assessment. However, the ongoing revision of the criticality methodology will partially fill this gap as it will include a more refined method for assessing the substitution potential.

The choice of supply risk as indicator presents some specific features: (i) the indicators that compose $\mathrm{SR}_{\mathrm{WGI}}$ (e.g. WGI and HHI) are calculated at global level (while the EI is assessed at EU level) or are based on expert judgment; recycling rate values are global estimates provided by UNEP (UNEP and International Resource Panel 2011); (ii) no thresholds or other subjective elements are included in this indicator apart from the selection of the exponent; and (iii) frequent updates of the CFs could provide consistent assessments.

Concerning the impact assessment of resources, different perspectives could be adopted, reflecting different viewpoints and policy priority (Dewulf et al. 2015). In the case of abiotic resources, at least three main perspectives can be envisaged: the depletion of mineral resources, their security of supply to the economic system and the environmental damage caused by their extraction. In order to put these different perspectives into practice in a LCIA, CFs have to be derived for each aspect, using specific indicators.

1. Resource depletion perspective: geological availability of resources is the main issue of concern. The abiotic depletion potential (ADP), indicator developed by CML (van Oers et al. 2002) and recommended by the International Reference Life Cycle Data System (ILCD) (EC-European Commission 2011b), is chosen as an indicator for quantifying this aspect; it measures the impact as the ratio between resource extraction "environment". In fact, e.g. emissions into air may lead to human health impacts, which may be part of a societal concern. Similarly, for the supply risk, the resources extracted and accounted for in ELCA are used as input for modelling a socio-economic concern related to availability and security of supply of certain resources

and square reserves in relation to a reference element (antimony). The quantification of resource depletion in LCA has been widely debated (e.g. Klinglmaier et al. 2013; Stewart and Weidema 2005), and the use of the ADP indicator in LCA is criticized, as the reserve data used for its calculation could not reflect the real resource availability (Drielsma et al. 2015). Discussing the feasibility of this indicator is beyond the scope of this paper, but it seeks to illustrate hotspot resources in terms of scarcity, using the indicators that are used as common practice in LCA and recommended by the ILCD. Two options of ADP are compared in Table 2, calculated using reserve base and ultimate reserve (Guinee et al. 2002).

2. Socio-economic and geo-political perspective: resource security is the main problem with resources, and there is a risk of supply disruptions due to supply concentration and political instability of the producing countries. This aspect is characterized using $\mathrm{SR}_{\mathrm{WGI}}$ data provided in the EC study on CRM, as midpoint CFs. The supply risk is used as a proxy indicator for quantifying the impact of resource use from a socio-political perspective (methodological issues related to the use of supply risk values as CFs are in the Electronic Supplementary Material). The EI of raw materials (the second variable used in the criticality matrix) is not taken into account since it relates to the European economy as a whole and could be less meaningful for supply chain analysts at corporate level.

The $\mathrm{SR}_{\mathrm{WGI}}$ dataset has low variability; therefore, the relative difference between materials in terms of security would be not well represented if these values are applied as linear weighting factors. ${ }^{2}$

\footnotetext{
${ }^{2}$ It has to be noted that the supply risk factors are applied for a wide range of materials and not only those resulting as critical in the last EU assessment (EC-European Commission 2014). Therefore, the difference between "critical" and "nearly critical" materials (i.e., having values of supply risk close to the critical but placed outside the criticality threshold) is better captured in the impact assessment phase.
} 
Table 2 Characterization factors derived from different perspectives on resource assessment

\begin{tabular}{|c|c|c|c|c|c|c|c|c|}
\hline \multirow[b]{3}{*}{ Resource } & \multicolumn{8}{|c|}{ Perspectives } \\
\hline & \multicolumn{2}{|c|}{ resource depletion } & \multicolumn{4}{|c|}{$\begin{array}{l}\text { socio-economic and geo-political } \\
\text { concerns }\end{array}$} & \multirow{2}{*}{$\begin{array}{c}\begin{array}{l}\text { socio-economic } \\
+ \text { depletion }\end{array} \\
\text { SRWGI/R } \\
\end{array}$} & \multirow{2}{*}{$\begin{array}{c}\begin{array}{c}\text { Environmenta } \\
\text { concern }\end{array} \\
\text { Env. Rank }\end{array}$} \\
\hline & ADPrb & ADPult. & SRwGI & $\mathrm{SR}_{W G I^{\wedge 3}}$ & SRWGI^6 & SRwGI/P & & \\
\hline Aluminium & $2.53 \mathrm{E}-05$ & $1.09 \mathrm{E}-09$ & 0.43 & 7.95E-02 & $6.32 \mathrm{E}-03$ & $1.04 \mathrm{E}-08$ & $1.54 \mathrm{E}-11$ & 5.4 \\
\hline Antimony & $1.00 \mathrm{E}+00$ & $1.00 \mathrm{E}+00$ & 2.54 & $1.64 \mathrm{E}+01$ & $2.69 \mathrm{E}+02$ & $1.69 \mathrm{E}-05$ & $1.41 \mathrm{E}-06$ & 5.9 \\
\hline Barytes & n.a. & n.a. & 1.74 & $5.27 \mathrm{E}+00$ & $2.78 \mathrm{E}+01$ & $2.18 \mathrm{E}-07$ & n.a. & n.a. \\
\hline Bauxite & n.a. & n.a. & 0.57 & $1.85 \mathrm{E}-01$ & $3.43 \mathrm{E}-02$ & $2.77 \mathrm{E}-09$ & 2.04E-11 & n.a. \\
\hline Bentonite & n.a. & n.a. & 0.37 & 5.07E-02 & $2.57 \mathrm{E}-03$ & 2.64E-08 & n.a. & n.a. \\
\hline Beryllium & $1.26 \mathrm{E}-05$ & $1.26 \mathrm{E}-05$ & 1.45 & $3.05 \mathrm{E}+00$ & $9.29 \mathrm{E}+00$ & $7.51 \mathrm{E}-03$ & n.a. & n.a. \\
\hline Boron/borate & 4.27E-03 & 4.27E-03 & 0.95 & 8.57E-01 & 7.35E-01 & 2.07E-07 & n.a. & 3.3 \\
\hline Chromium & $1.96 \mathrm{E}-05$ & 4.43E-04 & 1.01 & $1.03 E+00$ & $1.06 \mathrm{E}+00$ & $9.10 \mathrm{E}-08$ & $2.20 \mathrm{E}-09$ & 5.9 \\
\hline Clays & n.a. & n.a. & 0.27 & 1.97E-02 & 3.87E-04 & $9.35 \mathrm{E}-09$ & n.a. & 2.6 \\
\hline Cobalt & $2.56 \mathrm{E}-02$ & 1.57E-05 & 1.63 & $4.33 \mathrm{E}+00$ & $1.88 \mathrm{E}+01$ & $1.50 \mathrm{E}-05$ & 2.17E-07 & 5.6 \\
\hline Cooking coal & n.a. & n.a. & 1.18 & $1.64 \mathrm{E}+00$ & $2.70 \mathrm{E}+00$ & $1.64 \mathrm{E}-10$ & n.a. & 2.6 \\
\hline Copper & $2.50 \mathrm{E}-03$ & $1.37 \mathrm{E}-03$ & 0.22 & $1.06 \mathrm{E}-02$ & 1.13E-04 & $1.38 \mathrm{E}-08$ & $3.24 \mathrm{E}-10$ & 5.4 \\
\hline Diatomite & n.a. & n.a. & 0.24 & $1.38 \mathrm{E}-02$ & $1.91 \mathrm{E}-04$ & $1.40 \mathrm{E}-07$ & n.a. & n.a. \\
\hline Feldspar & n.a. & n.a. & 0.35 & 4.29E-02 & $1.84 \mathrm{E}-03$ & $1.70 \mathrm{E}-08$ & n.a. & n.a. \\
\hline Fluorspar & n.a. & n.a. & 1.72 & $5.09 \mathrm{E}+00$ & $2.59 E+01$ & $2.92 \mathrm{E}-07$ & n.a. & 3.8 \\
\hline Gallium & $6.30 \mathrm{E}-03$ & $1.46 \mathrm{E}-07$ & 1.82 & $6.03 E+00$ & $3.63 E+01$ & $4.50 \mathrm{E}-03$ & n.a. & 6.5 \\
\hline Germanium & $1.95 \mathrm{E}+04$ & $6.52 \mathrm{E}-07$ & 1.94 & $7.30 \mathrm{E}+00$ & $5.33 \mathrm{E}+01$ & $1.63 \mathrm{E}-02$ & n.a. & n.a. \\
\hline Gold & $3.60 \mathrm{E}+01$ & $5.20 \mathrm{E}+01$ & 0.15 & $3.38 \mathrm{E}-03$ & 1.14E-05 & $5.69 \mathrm{E}-05$ & $2.88 \mathrm{E}-06$ & 9.6 \\
\hline Gypsum & n.a. & n.a. & 0.47 & $1.04 \mathrm{E}-01$ & $1.08 \mathrm{E}-02$ & 3.35E-09 & n.a. & n.a. \\
\hline Hafnium & n.a. & n.a. & 0.43 & $7.95 \mathrm{E}-02$ & $6.32 \mathrm{E}-03$ & $6.72 \mathrm{E}-03$ & n.a. & n.a. \\
\hline Indium & $5.55 \mathrm{E}+02$ & $6.89 \mathrm{E}-03$ & 1.8 & $5.83 \mathrm{E}+00$ & $3.40 \mathrm{E}+01$ & $2.96 \mathrm{E}-03$ & n.a. & 7.3 \\
\hline Iron & $1.66 \mathrm{E}-06$ & $5.24 \mathrm{E}-08$ & 0.5 & $1.25 \mathrm{E}-01$ & $1.56 \mathrm{E}-02$ & $3.93 \mathrm{E}-10$ & $2.94 \mathrm{E}-13$ & 2.3 \\
\hline Limestone & n.a. & n.a. & 0.38 & $5.49 \mathrm{E}-02$ & $3.01 \mathrm{E}-03$ & 4.72E-09 & n.a. & 1.6 \\
\hline Lithium & $1.33 \mathrm{E}-02$ & 1.15E-05 & 0.65 & $2.75 \mathrm{E}-01$ & $7.54 \mathrm{E}-02$ & $1.04 \mathrm{E}-05$ & $5.00 \mathrm{E}-08$ & 5.8 \\
\hline Magnesite & n.a. & n.a. & 2.15 & $9.94 \mathrm{E}+00$ & $9.88 \mathrm{E}+01$ & n.a. & n.a. & 3.9 \\
\hline Magnesium & $2.48 \mathrm{E}-06$ & $2.02 \mathrm{E}-09$ & 2.53 & $1.62 \mathrm{E}+01$ & $2.62 \mathrm{E}+02$ & $3.35 \mathrm{E}-06$ & $1.05 \mathrm{E}-06$ & 5.2 \\
\hline Manganese & $2.35 \mathrm{E}-05$ & $2.54 \mathrm{E}-06$ & 0.43 & 7.95E-02 & $6.32 \mathrm{E}-03$ & $2.76 \mathrm{E}-08$ & $6.83 \mathrm{E}-10$ & n.a. \\
\hline Molybdenum & 7.11E-02 & $1.78 \mathrm{E}-02$ & 0.86 & $6.36 \mathrm{E}-01$ & 4.05E-01 & $3.44 \mathrm{E}-06$ & $7.82 \mathrm{E}-08$ & n.a. \\
\hline Natural Graphite & n.a. & n.a. & 2.2 & $1.06 \mathrm{E}+01$ & $1.13 \mathrm{E}+02$ & $2.00 \mathrm{E}-06$ & n.a. & 2.8 \\
\hline Nickel & $4.18 \mathrm{E}-03$ & $6.53 \mathrm{E}-05$ & 0.24 & $1.38 \mathrm{E}-02$ & $1.91 \mathrm{E}-04$ & $1.34 \mathrm{E}-07$ & 3.20E-09 & 5.9 \\
\hline Niobium & $6.55 \mathrm{E}-02$ & $1.93 \mathrm{E}-05$ & 2.46 & $1.49 \mathrm{E}+01$ & $2.22 \mathrm{E}+02$ & $3.89 \mathrm{E}-05$ & $6.15 \mathrm{E}-07$ & n.a. \\
\hline Perlite & n.a. & n.a. & 0.28 & $2.20 \mathrm{E}-02$ & $4.82 \mathrm{E}-04$ & $1.58 \mathrm{E}-07$ & n.a. & n.a. \\
\hline $\begin{array}{l}\text { Phosphorus/phosphate } \\
\text { rock }\end{array}$ & $5.52 \mathrm{E}-06$ & $5.52 \mathrm{E}-06$ & 1.09 & $1.30 \mathrm{E}+00$ & $1.68 \mathrm{E}+00$ & $2.02 \mathrm{E}-08$ & n.a. & n.a. \\
\hline Platinum/PGM & $2.22 \mathrm{E}+00$ & $2.22 \mathrm{E}+00$ & 1.18 & $1.64 \mathrm{E}+00$ & $2.70 E+00$ & $2.06 \mathrm{E}-03$ & $1.79 \mathrm{E}-05$ & 9.1 \\
\hline Potash & $1.60 \mathrm{E}-08$ & n.a. & 0.21 & $9.26 \mathrm{E}-03$ & $8.58 \mathrm{E}-05$ & $5.78 \mathrm{E}-09$ & n.a. & n.a. \\
\hline Pulp wood & n.a. & n.a. & 0.12 & $1.73 \mathrm{E}-03$ & 2.99E-06 & $6.48 \mathrm{E}-10$ & n.a. & n.a. \\
\hline
\end{tabular}


Table 2 (continued)

\begin{tabular}{|c|c|c|c|c|c|c|c|c|}
\hline \multirow[b]{3}{*}{ Resource } & \multicolumn{8}{|c|}{ Perspectives } \\
\hline & \multicolumn{2}{|c|}{ resource depletion } & \multicolumn{4}{|c|}{$\begin{array}{c}\text { socio-economic and geo-political } \\
\text { concerns }\end{array}$} & \multirow{2}{*}{$\begin{array}{c}\begin{array}{l}\text { socio-economic } \\
\text { + depletion }\end{array} \\
\text { SRwGl/R } \\
\end{array}$} & \multirow{2}{*}{$\begin{array}{c}\begin{array}{c}\text { Environmental } \\
\text { concern }\end{array} \\
\text { Env. Rank } \\
\end{array}$} \\
\hline & ADPrb & ADPult. & SRwGI & $S_{\text {RGI}}{ }^{\wedge} \mathbf{3}$ & SRWGi^6 & SRwGI/P & & \\
\hline REE (Heavy) & $5.69 \mathrm{E}-04$ & n.a. & 4.67 & $1.02 E+02$ & $1.04 E+04$ & 4.25E-05 & $4.25 \mathrm{E}-08$ & n.a. \\
\hline REE (Light) & n.a. & n.a. & 3.13 & 3.07E+01 & $9.40 \mathrm{E}+02$ & n.a. & n.a. & 5.8 \\
\hline Rhenium & $3.19 \mathrm{E}+01$ & $6.03 \mathrm{E}-01$ & 0.89 & $7.05 \mathrm{E}-01$ & 4.97E-01 & $1.76 \mathrm{E}-02$ & n.a. & n.a. \\
\hline Sawn Softwood & n.a. & n.a. & 0.15 & $3.38 \mathrm{E}-03$ & $1.14 \mathrm{E}-05$ & 5.17E-10 & n.a. & 6.2 \\
\hline Scandium & n.a. & n.a. & 1.12 & $1.40 \mathrm{E}+00$ & $1.97 \mathrm{E}+00$ & $1.12 \mathrm{E}-01$ & n.a. & n.a. \\
\hline Selenium & $7.35 E+00$ & $1.94 \mathrm{E}-01$ & 0.19 & $6.86 \mathrm{E}-03$ & 4.70E-05 & $7.04 \mathrm{E}-05$ & $1.94 \mathrm{E}-06$ & n.a. \\
\hline Silica sand & n.a. & n.a. & 0.32 & $3.28 \mathrm{E}-02$ & $1.07 \mathrm{E}-03$ & 2.64E-09 & n.a. & n.a. \\
\hline Silicon & $1.40 \mathrm{E}-11$ & $1.40 \mathrm{E}-11$ & 1.63 & $4.33 E+00$ & $1.88 \mathrm{E}+01$ & $8.76 \mathrm{E}-07$ & n.a. & 4.8 \\
\hline Silver & $8.42 \mathrm{E}+00$ & $1.18 \mathrm{E}+00$ & 0.73 & $3.89 \mathrm{E}-01$ & $1.51 \mathrm{E}-01$ & $3.13 \mathrm{E}-05$ & $1.35 \mathrm{E}-06$ & 6.9 \\
\hline Talc & n.a. & n.a. & 0.26 & $1.76 \mathrm{E}-02$ & $3.09 \mathrm{E}-04$ & $3.38 \mathrm{E}-08$ & n.a. & n.a. \\
\hline Tantalum & $1.15 \mathrm{E}+01$ & $4.06 \mathrm{E}-05$ & 0.62 & $2.38 \mathrm{E}-01$ & $5.68 \mathrm{E}-02$ & $9.10 \mathrm{E}-04$ & 4.13E-06 & n.a. \\
\hline Tellurium & $7.21 \mathrm{E}+00$ & 4.07E+01 & 0.19 & $6.86 \mathrm{E}-03$ & 4.70E-05 & 4.22E-04 & 7.92E-06 & n.a. \\
\hline Tin & $1.15 \mathrm{E}-01$ & $1.62 \mathrm{E}-02$ & 0.82 & $5.51 \mathrm{E}-01$ & $3.04 \mathrm{E}-01$ & $2.79 \mathrm{E}-06$ & $1.67 \mathrm{E}-07$ & n.a. \\
\hline Titanium & $1.52 \mathrm{E}-03$ & $2.79 \mathrm{E}-08$ & 0.13 & $3.04 \mathrm{E}-01$ & 4.83E-06 & $2.14 \mathrm{E}-08$ & n.a. & n.a. \\
\hline Tungsten & $2.54 \mathrm{E}-01$ & $4.52 \mathrm{E}-03$ & 1.99 & $7.88 \mathrm{E}+00$ & $6.21 \mathrm{E}+01$ & $2.72 \mathrm{E}-05$ & n.a. & n.a. \\
\hline Vanadium & 4.93E-03 & 7.70E-07 & 0.82 & 5.51E-01 & $3.04 \mathrm{E}-01$ & $1.33 \mathrm{E}-05$ & $5.86 \mathrm{E}-08$ & n.a. \\
\hline Zinc & $3.65 \mathrm{E}-03$ & $5.38 \mathrm{E}-04$ & 0.45 & $9.11 \mathrm{E}-02$ & 8.30E-03 & 3.70E-08 & $1.80 \mathrm{E}-09$ & 5.4 \\
\hline
\end{tabular}

In some cases, the nomenclature used for the materials differs from an indicator to another (e.g. potassium/potash) or a group of materials is taken into account instead of a single element (e.g. for supply risk is calculated for platinum group metals, while in ADP, the characterization factors refer to platinum only). In the case of rare earths (REE), we calculated the average ADP for heavy and light REE, while supply risk factors are already presented as heavy and light REE in the EU study

$A D P r b$ abiotic depletion potential calculated using reserve base data, $A D P u l t$ abiotic depletion potential calculated using ultimate reserve, $S R_{W G I}$ supply risk based on World Governance Index, $P$ world production in 2010 (data from EC 2014), $R$ reserves in 2013 (data retrieved from USGS), ENV. RANK environmental ranking based on results of the life cycle impact assessment for different environmental categories, aggregated in a composite indicator

Therefore, in order to obtain factors that could better represent the supply risk, different options are explored:

(a) Raising the values with an exponent that could spread the resulting values in a wider range, as the choice of the exponential is subjective, and the function to be used (that better highlights resource hotpots in terms of supply risk) is more a political decision rather than a scientific fact; in this study, the exponents 1,3 and 6 are tested $\left(\mathrm{SR}_{\mathrm{WGI}} ; \mathrm{SR}_{\mathrm{WGI}}{ }^{\wedge} 3\right.$; $\left.\mathrm{SR}_{\mathrm{WGI}}{ }^{\wedge} 6\right)$ and the impact assessment results from the three functions are compared.

(b) Dividing the values of supply risk by a measure of the size of the market, e.g. the world mine production in a given year, in order to assign more importance to specialty materials having small markets $\left(\mathrm{SR}_{\mathrm{WGI}} / \mathrm{P}\right)$. It is assumed, indeed, that smaller markets imply a higher price volatility due to the higher likelihood of producer dominance and less flexibility to adjust to an increase in demand (Buijs et al. 2012). (c) Dividing the values of supply risk by geological reserve data, in order to include, in the assessment, an element related to resource availability and obtain a mixed approach on socio-economic and depletion aspects $\left(\mathrm{SR}_{\mathrm{WGI}} / \mathrm{R}\right)$. Details on the methodology used to obtain the CF and background data are reported in the Electronic Supplementary Material.

3. Environmental perspective: the focus is on the environmental impact due to the extraction of raw materials. In this case, results of the life cycle impact assessment for different environmental categories are aggregated in a composite indicator in order to provide an indication of the severity of environmental impacts associated with resource extraction, together with a ranking (ENV. RANK). The resulting figures should be interpreted as average order of magnitude of the impacts. Details of the calculation of the composite indicators are reported in the Electronic Supplementary Material.

Table 2 reports the abovementioned perspectives on abiotic resources and shows the corresponding CFs that could be used to quantify the related impact. 
The colour code used in Table 2 highlights the hotspot materials across the different perspectives: while from a resource depletion point of view, germanium (for the ADP calculated with reserve base) and gold and tellurium (for the ADP calculated with ultimate reserve) have the highest score, the main concern for resource security is on rare earths (REE), ${ }^{3}$ antimony, magnesium and niobium. Considering the market size (i.e. $\mathrm{SR}_{\mathrm{WGI}} / \mathrm{P}$ ), scandium, rhenium and germanium present the highest values, while combining the socio-economic perspective with the depletion one (through the ratio between supply risk and reserve data), it is possible to see that platinum group metals (PGM) are the main priority materials, followed by tellurium, gold, silver and antimony. The environmental concerns, e.g. those stemming from the ENV. RANK, resulting from a LCA of the extraction, point at gold and platinum first, even though these datasets present many data gaps.

\section{Testing the inclusion of criticality in supply chain analysis}

Characterizing resources based on their supply risk may support eco-design and resource policies. A life cycle-based assessment is fundamental to identify where critical resources are used within supply chains, in order to optimize CRM use, explore substitution options and enhance recovery in waste management.

The four different options of CFs for the socio-economic and geo-political perspective displayed in Table 2 have been tested performing the impact assessment of a set of 50 process and products, using LC inventories from the Ecoinvent database (v2), across different dataset categories: materials, energy, electronics, transport and construction (full list in the Electronic Supplementary Material). Based on the dominance of a specific material in the inventory (in mass), a clustering has been performed in order to get to six groups of products having similar material composition in terms of shares over the total mass in input (in the Electronic Supplementary Material). The sets of CFs for resource security have been tested on the full set of process and products.

In order to understand the effect of the choice of the algorithm to be used for translating $\mathrm{SR}_{\mathrm{WGI}}$ factors into CFs for use in LCA, a comparative exercise was done for several raw materials (iron, clay, gallium, platinum, chromium and magnesium) (see Electronic Supplementary Material). For each of the raw material, a comparison between the contribution in mass to the total inventory ( $x$ axes) and the contribution to the overall criticality scores calculated ( $y$ axes) was performed. By applying the methodology $\mathrm{SR}_{\mathrm{WGI}}$, it clearly emerges that the share in mass dominates the impacts, making the role of

\footnotetext{
$\overline{{ }^{3} \text { Disaggregated }}$ data for rare earth elements would provide a better insight into the supply risk of the different materials. The actual data availability, however, does not allow for a better specification.
}

characterization almost negligible. The opposite holds when applying $\mathrm{SRWGI}^{\wedge} 6$ or $\mathrm{SR}_{\mathrm{WGI}} / \mathrm{P}$, as the share in mass over the inventory is very often negligible. Discrepancies from these trends are to be interpreted as deviations due to the specific characteristics of the process or product analyzed.

Gallium and PGM present the typical behaviour of CRMs: they are used in small quantities and their share over the total mass is almost negligible, very often below the cut-off values generally used in LCA. In this case, by adopting $\mathrm{SR}_{\mathrm{WGI}} / \mathrm{P}$, it is possible to see that regardless of the little quantities, the contribution to the criticality score can be extremely high. Instead, in the results obtained by applying $\mathrm{SR}_{\mathrm{WGI}}$ and $\mathrm{SR}_{\mathrm{WGI}} \wedge 6$ their contribution is almost negligible. In the case of magnesium, $\mathrm{SR}_{\mathrm{WGI}} \wedge 6$ shows higher values than $\mathrm{SR}_{\mathrm{WGI}} / \mathrm{P}$. This is due to the fact that production volume of this raw material is not small as in case of, e.g. gallium and platinum. In the case of chromium, it is difficult to identify a clear pattern, as both mass-wide and criticality-wise, it is not one of the major contributors. The results are likely to be influenced by the performance of other raw materials included in the inventory rather than the chromium itself.

Moreover, focusing on the results for a specific product (e.g. a laptop), the differences in the contribution analysis due to the application of different indicators of Table 2 are evident (Table 3 and Fig. 3). The IA results are displayed in comparison with the mass contribution, i.e. the amount of materials (in $\mathrm{kg}$ ) that are embodied in the life cycle of products. The impacts in terms of resource depletion and environmental performance of the material are also shown in Fig. 3. This comparison allows highlighting the contribution of the CFs to the total impact in comparison to the contribution of the mass content. As displayed also in Fig. 3, clay and iron are the most relevant materials in terms of mass, when applying the $\mathrm{CF} \mathrm{SG}_{\mathrm{WGI}}$ (without any exponent) and also for the environmental perspective. Applying the exponents 3 and 6 to the $\mathrm{SG}_{\mathrm{WGI}}$, the contribution of mass decreases and the impact is more influenced by the CF, i.e. by a high supply risk factor. In this example, magnesium appears as the main contributor in the options $\mathrm{SR}_{\mathrm{WGI}} \wedge$ and $\mathrm{SR}_{\mathrm{WGI}} \wedge$, in spite of its small contribution in terms of mass. Therefore, the application of an exponent to the SR has the effect of amplifying the supply risk impact, making it more visible even if the amounts used are small in terms of mass, as in the case of many CRMs. To a minor extent, also, rare earths show a similar behaviour, being irrelevant in terms of mass and when using the $\mathrm{SG}_{\mathrm{WGI}}$ as such as $\mathrm{CF}$, but gaining a bigger contribution in the option $\mathrm{SR}_{\mathrm{WGI}} \wedge$.

Looking at the scarcity perspective (ADP, reserve base), indium and gold are the hotspot resources, contributing together to more than $80 \%$ of the total impact. Being the reserve base data used for the calculation of ADP based on the reference year 1999 , this outcome is likely to poorly reflect the actual material scarcity. Updated ADP values would be needed for obtaining a more realistic assessment. Moreover, as USGS (that reported reserve base data since 1980) had ceased estimating these figures, ADP should be recalculated using, e.g. updated reserve 
Table 3 Resource security impact assessment results: example for a computer laptop using the four sets of criticality indicators

\begin{tabular}{|c|c|c|c|c|c|c|c|}
\hline \multirow[b]{2}{*}{ Resources } & \multicolumn{7}{|c|}{$\begin{array}{c}\text { Inventory (mass) and impact assessment results using different CFs for } \\
\text { resources }\end{array}$} \\
\hline & $\begin{array}{l}\text { Mass } \\
(\mathrm{kg})\end{array}$ & SRwGI & $S_{W_{G I}} \wedge \mathbf{3}$ & $\mathrm{SR}_{\mathrm{WGI}}{ }^{\wedge} 6$ & SRwGI/P & $\begin{array}{c}\text { ADP } \\
\text { (kg Sb eq.) }\end{array}$ & $\begin{array}{l}\text { ENV. } \\
\text { SCORE }\end{array}$ \\
\hline Aluminium & 4.23E-01 & $1.82 \mathrm{E}-01$ & 3.36E-02 & $2.67 \mathrm{E}-03$ & 4.40E-09 & 1.07E-05 & $2.28 \mathrm{E}+00$ \\
\hline Antimony & $9.20 \mathrm{E}-08$ & $2.34 \mathrm{E}-07$ & $1.51 \mathrm{E}-06$ & $2.47 \mathrm{E}-05$ & $1.56 \mathrm{E}-12$ & $9.20 \mathrm{E}-08$ & $5.43 \mathrm{E}-07$ \\
\hline Barite & 4.17E-02 & $7.25 \mathrm{E}-02$ & $2.20 \mathrm{E}-01$ & $1.16 \mathrm{E}+00$ & $9.06 \mathrm{E}-09$ & $0.00 E+00$ & $0.00 \mathrm{E}+00$ \\
\hline Borates & 8.37E-05 & $7.95 \mathrm{E}-05$ & $7.18 \mathrm{E}-05$ & $6.15 \mathrm{E}-05$ & $1.73 \mathrm{E}-11$ & $3.58 \mathrm{E}-07$ & $2.76 \mathrm{E}-04$ \\
\hline Chromium & $7.38 \mathrm{E}-02$ & $7.46 \mathrm{E}-02$ & $7.61 \mathrm{E}-02$ & $7.84 \mathrm{E}-02$ & $6.71 \mathrm{E}-09$ & $1.45 \mathrm{E}-06$ & 4.36E-01 \\
\hline Clay & $3.46 \mathrm{E}+00$ & 9.35E-01 & $6.82 \mathrm{E}-02$ & $1.34 \mathrm{E}-03$ & $3.24 \mathrm{E}-08$ & $0.00 \mathrm{E}+00$ & $9.01 \mathrm{E}+00$ \\
\hline Cobalt & $1.14 \mathrm{E}-04$ & $1.86 \mathrm{E}-04$ & 4.93E-04 & $2.14 \mathrm{E}-03$ & $1.70 \mathrm{E}-09$ & $2.92 \mathrm{E}-06$ & $6.38 \mathrm{E}-04$ \\
\hline Copper & $5.26 \mathrm{E}-01$ & $1.16 \mathrm{E}-01$ & $5.61 \mathrm{E}-03$ & 5.97E-05 & 7.24E-09 & $1.32 \mathrm{E}-03$ & $2.84 \mathrm{E}+00$ \\
\hline Diatomite & $1.27 \mathrm{E}-06$ & $3.04 \mathrm{E}-07$ & $1.75 \mathrm{E}-08$ & $2.42 \mathrm{E}-10$ & $1.77 \mathrm{E}-13$ & $0.00 \mathrm{E}+00$ & $0.00 E+00$ \\
\hline Feldspar & $2.89 \mathrm{E}-06$ & $1.01 \mathrm{E}-06$ & $1.24 \mathrm{E}-07$ & $5.32 \mathrm{E}-09$ & 4.92E-14 & $0.00 E+00$ & $0.00 \mathrm{E}+00$ \\
\hline Fluorspar & $4.73 \mathrm{E}-02$ & 8.13E-02 & $2.41 \mathrm{E}-01$ & $1.22 \mathrm{E}+00$ & $1.38 \mathrm{E}-08$ & $0.00 E+00$ & $1.80 \mathrm{E}-01$ \\
\hline Gallium & $1.31 \mathrm{E}-04$ & $2.39 \mathrm{E}-04$ & 7.91E-04 & 4.77E-03 & $5.91 \mathrm{E}-07$ & $8.26 \mathrm{E}-07$ & $8.52 \mathrm{E}-04$ \\
\hline Gold & $6.60 \mathrm{E}-04$ & $9.90 \mathrm{E}-05$ & $2.23 \mathrm{E}-06$ & 7.52E-09 & $3.76 \mathrm{E}-08$ & 2.37E-02 & $6.34 \mathrm{E}-03$ \\
\hline Gypsum & $1.01 \mathrm{E}-01$ & 4.76E-02 & $1.05 \mathrm{E}-02$ & $1.09 \mathrm{E}-03$ & $3.40 \mathrm{E}-10$ & $0.00 \mathrm{E}+00$ & $0.00 \mathrm{E}+00$ \\
\hline Indium & $6.17 \mathrm{E}-05$ & 1.11E-04 & $3.60 \mathrm{E}-04$ & $2.10 \mathrm{E}-03$ & $1.82 \mathrm{E}-07$ & $3.42 \mathrm{E}-02$ & $4.50 \mathrm{E}-04$ \\
\hline Iron & $1.75 \mathrm{E}+00$ & 8.77E-01 & $2.19 \mathrm{E}-01$ & $2.74 \mathrm{E}-02$ & $6.89 \mathrm{E}-10$ & $2.91 \mathrm{E}-06$ & $4.03 E+00$ \\
\hline Lithium & $2.12 \mathrm{E}-03$ & $1.38 \mathrm{E}-03$ & $5.83 \mathrm{E}-04$ & $1.60 \mathrm{E}-04$ & $2.22 \mathrm{E}-08$ & $2.82 \mathrm{E}-05$ & $1.23 \mathrm{E}-02$ \\
\hline Magnesite & $1.66 \mathrm{E}-02$ & $3.57 \mathrm{E}-02$ & $1.65 \mathrm{E}-01$ & $1.64 \mathrm{E}+00$ & $6.05 \mathrm{E}-09$ & $0.00 \mathrm{E}+00$ & $6.48 \mathrm{E}-02$ \\
\hline Magnesium & $5.15 \mathrm{E}-01$ & $1.30 \mathrm{E}+00$ & $8.35 \mathrm{E}+00$ & $1.35 \mathrm{E}+02$ & $1.73 \mathrm{E}-06$ & $1.28 \mathrm{E}-06$ & $2.68 \mathrm{E}+00$ \\
\hline Manganese & $4.65 \mathrm{E}-02$ & $2.00 \mathrm{E}-02$ & $3.70 \mathrm{E}-03$ & $2.94 \mathrm{E}-04$ & $1.28 \mathrm{E}-09$ & $1.09 \mathrm{E}-06$ & $0.00 \mathrm{E}+00$ \\
\hline Molybdenum & $1.18 \mathrm{E}-02$ & $1.02 \mathrm{E}-02$ & $7.52 \mathrm{E}-03$ & $4.78 \mathrm{E}-03$ & 4.06E-08 & $8.41 \mathrm{E}-04$ & $0.00 \mathrm{E}+00$ \\
\hline Nickel & $1.89 \mathrm{E}-01$ & 4.54E-02 & $1.38 \mathrm{E}-01$ & $1.01 \mathrm{E}-01$ & $1.54 \mathrm{E}-08$ & 7.91E-04 & $1.12 \mathrm{E}+00$ \\
\hline PGM & $2.81 \mathrm{E}-06$ & 3.31E-06 & 4.61E-06 & $7.58 \mathrm{E}-06$ & $5.79 \mathrm{E}-09$ & $6.22 \mathrm{E}-06$ & $2.55 \mathrm{E}-05$ \\
\hline Potash & $7.53 \mathrm{E}-03$ & $1.58 \mathrm{E}-03$ & $6.98 \mathrm{E}-05$ & $6.46 \mathrm{E}-07$ & 4.35E-11 & $1.20 \mathrm{E}-10$ & $0.00 \mathrm{E}+00$ \\
\hline Rare Earths (light) & $1.61 \mathrm{E}-03$ & 7.53E-03 & $1.64 \mathrm{E}-01$ & $1.67 \mathrm{E}+01$ & $6.84 \mathrm{E}-08$ & 9.17E-07 & $0.00 \mathrm{E}+00$ \\
\hline Rare Earths (heavy) & $8.16 \mathrm{E}-06$ & $2.56 \mathrm{E}-05$ & $2.50 \mathrm{E}-04$ & $7.68 \mathrm{E}-03$ & $2.32 \mathrm{E}-10$ & $0.00 \mathrm{E}+00$ & 4.74E-05 \\
\hline Rhenium & $7.29 \mathrm{E}-10$ & $6.49 \mathrm{E}-10$ & $5.14 \mathrm{E}-10$ & $3.62 \mathrm{E}-10$ & $1.28 \mathrm{E}-11$ & $2.33 \mathrm{E}-08$ & $0.00 \mathrm{E}+00$ \\
\hline Sand & $7.75 \mathrm{E}-03$ & $2.48 \mathrm{E}-03$ & $2.54 \mathrm{E}-04$ & $8.32 \mathrm{E}-06$ & $2.05 \mathrm{E}-11$ & $0.00 \mathrm{E}+00$ & $0.00 \mathrm{E}+00$ \\
\hline Silver & $4.08 \mathrm{E}-04$ & $2.98 \mathrm{E}-04$ & $1.59 \mathrm{E}-04$ & $6.17 \mathrm{E}-05$ & $1.28 \mathrm{E}-08$ & $3.43 \mathrm{E}-03$ & $2.81 \mathrm{E}-03$ \\
\hline Talc & $9.21 \mathrm{E}-04$ & $2.39 \mathrm{E}-04$ & $1.62 \mathrm{E}-05$ & $2.84 \mathrm{E}-07$ & $3.11 \mathrm{E}-11$ & $0.00 \mathrm{E}+00$ & $0.00 \mathrm{E}+00$ \\
\hline Tantalum & $2.75 \mathrm{E}-04$ & $1.71 \mathrm{E}-04$ & $6.56 \mathrm{E}-05$ & $1.56 \mathrm{E}-05$ & $2.51 \mathrm{E}-07$ & $3.18 \mathrm{E}-03$ & $0.00 \mathrm{E}+00$ \\
\hline Tin & $1.37 \mathrm{E}-02$ & $1.12 \mathrm{E}-02$ & $9.66 \mathrm{E}-03$ & $6.81 \mathrm{E}-03$ & 4.16E-08 & $1.58 \mathrm{E}-03$ & $0.00 \mathrm{E}+00$ \\
\hline Zinc & $1.12 \mathrm{E}-01$ & $5.02 \mathrm{E}-02$ & $1.02 \mathrm{E}-02$ & $9.26 \mathrm{E}-04$ & 4.13E-09 & 4.07E-04 & $6.02 \mathrm{E}-01$ \\
\hline
\end{tabular}

The colour formatting allows visualizing the materials having higher impact in the different options of CF (red: highest impact; green: lowest impact) $S R_{W G I}$ supply risk based on World Governance Index, $P$ world production in 2010 (data from EC 2014), $R$ reserves in 2013 (data retrieved from USGS), $A D P$ abiotic depletion potential calculated using reserve base data, ENV. RANK environmental ranking based on results of the life cycle impact assessment for different environmental categories, aggregated in a composite indicator 
Fig. 3 Contribution analysis for a laptop: comparison of the results for resource characterization using different indicators

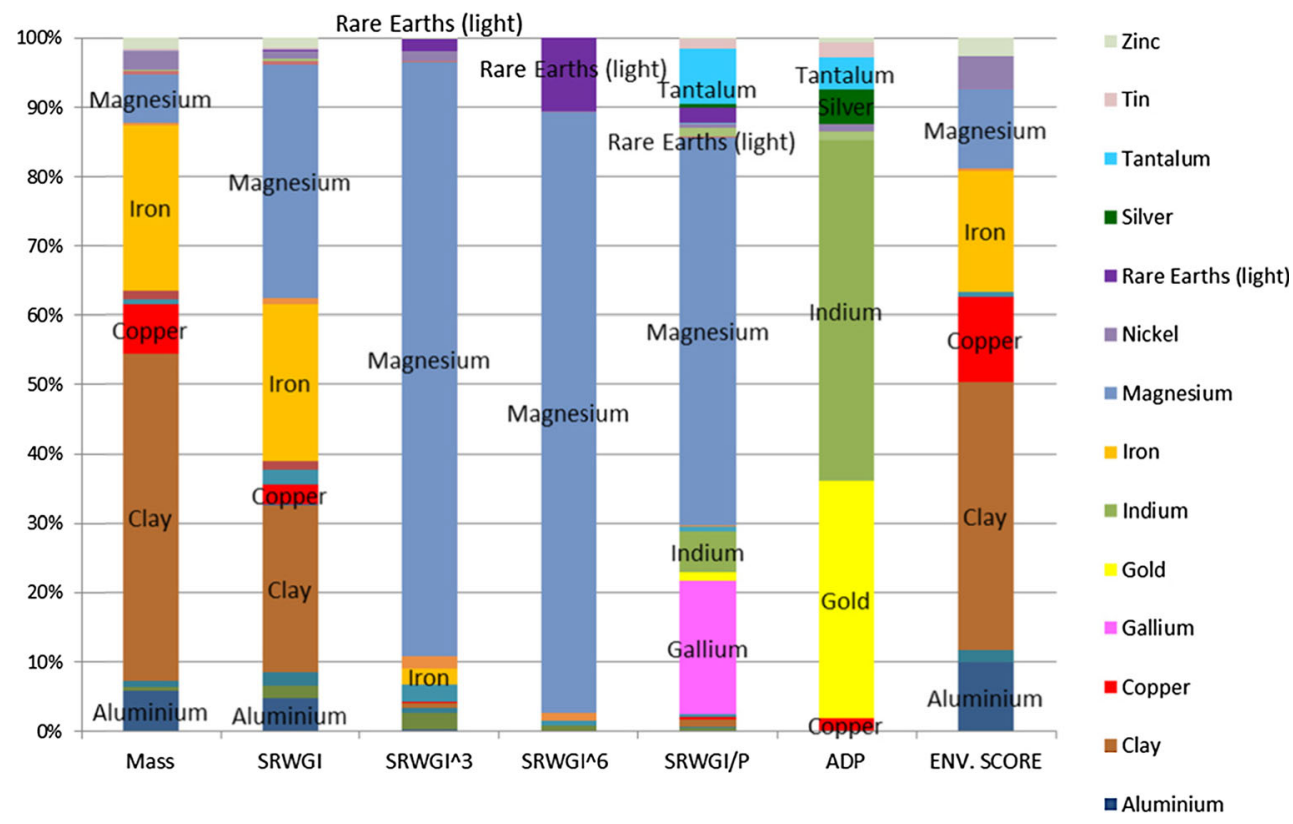

data. ${ }^{4}$ In the option $\mathrm{SR}_{\mathrm{WGI}} / \mathrm{P}$, the supply risk relates to the size of the market, using data on mine production in 2010. This allows highlighting the materials that are used in small amounts over the bulk materials. Therefore, gallium, indium and tantalum (all CRM in the EU assessment) have a higher contribution (in spite of its low mass in the inventory).

A similar behaviour as the one described for the impact assessment of computer laptop is shown by the impact assessment of other products (see Electronic Supplementary Material): using the supply risk factors as such for the characterization produces results that reflect the contribution of different materials in terms of mass ${ }^{5}$, using an exponent for the supply risk factor allows emphasizing the effect of supply risk at the expense of the mass (the higher the exponent, the more visible is this effect), and using the ratio between supply risk and production allows the small market materials to pop up, even if they are used in very small amounts.

The definition of the algorithms to be used is all but trivial. In this paper, only a limited set of mathematical functions was tested in order to underline their effect on the overall results. If the $\mathrm{SR}_{\mathrm{WGI}}$ factors are applied as such, it can be observed that the raw material contributing the most to criticality is clay. However, clay is an abundant resource and evenly distributed in the world, with no concentration of suppliers in a given country. Therefore, it does not make very much sense to use

\footnotetext{
${ }^{4}$ According to USGS definition, "reserves are defined as that part of the reserve base which could be economically extracted or produced at the time of determination" while reserve base is "that part of an identified resource that meets specified minimum physical and chemical criteria related to current mining and production practices, including those for grade, quality, thickness, and depth.” (USGS 2015)

5 The dominance of mass in the impact assessment results is discussed also in Schneider et al. (2014)
}

the factors as such, because clearly, the mass dominates over the CFs when calculating the impact associated to criticality.

No theory can sustain the choice of elevating at the power of 3 or 6 the $\mathrm{SR}_{\mathrm{WGI}}$ factors, and this choice can be considered as subjective as the choice of a set of weights for comparing incommensurable quantities. Nevertheless, such choices have been done in some impact assessment methods (e.g. the ADP methodology, see van Oers et al. 2002). These options are shown in this paper only to explain the effect of such arbitrary choice. The $\mathrm{SR}_{\mathrm{WGI}}$ factors are dimensionless, and they do not reflect the volumes of resource extracted, nor economic reserves of minerals. Thus, they only consider geographical distribution and governance, substitutability and recyclability regardless of the quantities of material entering the economic system. Combining $\mathrm{SR}_{\mathrm{WGI}}$ factors together with the inverse of total volumes of production (or reserve) of a given raw material leads to CFs scaled by extracted mass. Such factors represent the risk of supply chain disruption associated to a kilogram of resource extracted.

\section{Conclusions}

An increasing interest on resource criticality has emerged in both governmental and research contexts. Even though most of the interpretations of the criticality concept focus on economic and geopolitical aspects (like the risk of supply disruption), in this paper, we argued that resource criticality could be interpreted in a wider manner, taking into account the different perspectives on resources (e.g. scarcity, criticality and environmental) and, e.g. defining a hierarchy of needs that these resources would fulfil. Focusing on the socio-economic and geopolitical perspectives, the paper has shown how different options for the characterization of resource security and 
criticality concerns could be adopted for use in LCA, starting from the data on supply risk published by the EC study on CRMs. These options were tested on several LC inventories, applying the risk factors as CF in a LCIA.

The exercise performed in this study suggests that LCA is well positioned to include socio-economic and geopolitical considerations related to the use of material resources, essentially a socio-economic indicator. The variable $\mathrm{SR}_{\mathrm{WGI}}$, i.e. supply risk due to low governance, when used as CFs does not well represent the relative difference in raw material security, and the impact depends mainly on the masses. Applying an exponent to the supply risk dataset, the values are spread on a wider range and it is possible to spot the CRM among the resources within an inventory. The choice is based rather on how important is the need of identifying a CRM in the inventory in order to optimize CRM use, explore substitution options and enhance recovery in waste management. This choice, which might apparently look to be at the level of technical details, has a substantial effect on the results. In the third option, the supply risk is related to the annual mine production, which indicates the market size; this method gives more importance to specialty metals and reflects more closely the results of the EC assessment on CRM. We would therefore recommend the use of this latter option for assessing resource security in LCA when there is the need of enhancing strategic and socio-economic considerations.

The study also discloses the feasibility of introducing socio-economic considerations related to resources in LCA at impact assessment level, proposing a differentiation between traditional LCA and social LCA that is not based on the nature of the impacts (social, environmental, economic), but, at inventory level, on the type of interventions that are producing that impacts. In the case of environmental intervention and exchange of biophysical substances (in terms of both emissions and resource extractions), LCA would be the most appropriate methodology.

Acknowledgments The work on supply risk characterization factor development was partly financially supported by the Directorate General Environment (DG ENV) of the European Commission in the context of the Administrative Arrangement "Technical support for Environmental Footprinting, material efficiency in product policy and the European Platform on LCA" (No. 07.0307/ENV/2013/SI2.668694/ A1). We would like to thank Cynthia E. L. Latunussa for her support in data retrieving and elaboration.

\section{Compliance with ethical standards}

Conflict of interest The authors declare that they have no conflict of interest.

Open Access This article is distributed under the terms of the Creative Commons Attribution 4.0 International License (http:// creativecommons.org/licenses/by/4.0/), which permits unrestricted use, distribution, and reproduction in any medium, provided you give appropriate credit to the original author(s) and the source, provide a link to the Creative Commons license, and indicate if changes were made.

\section{References}

Achzet B, Helbig C (2013) How to evaluate raw material supply risksan overview. Resour Pol 38:435-447

AEA Technology (2010) Review of the future resource risks faced. UK Business and an Assessment of Future Viability, London

Benson SG, Dundis SP (2003) Understanding and motivating health care employees: integrating Maslow's hierarchy of needs, training and technology. J Nurs Manag 11:315-320

BGS (2012) Risk list 2011. Nottingham

Bleischwitz R, Bahn-Walkowiak B, Ekardt F, Feldt H, Fuhr L (2012) International Resource Politics: new challenges demanding new governance approaches for a green economy. Berlin

Buchert M, Schüler D, Bleher D (2009) Critical metals for future sustainable technologies and their recycling potential. Paris

Buijs B, Sievers H, Tercero Espinoza LA (2012) Limits to the critical raw materials approach. Waste Resour Manag 165:7

CCMI CER and NRC (2008) Minerals, critical minerals, and the U.S. economy. The National Academies Press

de Haes HAU, Jolliet O, Finnveden G, Hauschild M, Krewitt W, MüllerWenk R (1999) Best available practice regarding impact categories and category indicators in life cycle impact assessment. Int J Life Cycle Assess 4(2):66-74. doi:10.1007/BF02979403

Dewulf J, Benini L, Mancini L, Sala S, Blengini GA, Ardente F, Recchioni M, Maes J, Pant R, Pennington D (2015) Rethinking the area of protection "natural resources" in life cycle assessment. Environ Sci Technol 49:5310-5317

Dominati E, Patterson M, Mackay A (2010) A framework for classifying and quantifying the natural capital and ecosystem services of soils. Ecol Econ 69:1858-1868

Drielsma JA, Russell-Vaccari AJ, Drnek T, Brady T, Weihed P, Mistry M, Simbor LP (2015) Mineral resources in life cycle impact assessment - defining the path forward. Int J Life Cycle Assess 21:85-105

EC-European Commission (2008) The raw materials initiative- meeting our critical needs for growth and jobs in Europe

EC-European Commission (2010) Critical raw materials for the EU. Report of the Ad-Hoc Working Group on Defining Critical Raw Materials, Brussels

EC-European Commission (2011a) A resource-efficient Europe-flagship initiative under the Europe 2020 strategy

EC-European Commission (2011b) ILCD handbook-recommendations for life cycle impact assessment in the European context. European Commission, Joint Research Centre, Institute for Environment and Sustainability

EC-European Commission (2014) Report on critical raw materials for the EU-report of the Ad hoc Working Group on defining critical raw materials

Erdmann L, Graedel TE (2011) Criticality of non-fuel minerals: a review of major approaches and analyses. Environ Sci Technol 45:7620 7630

Frondel M, Grösche P, Huchtemann D, Oberheitmann A, Peters J, Angerer G (2005) Trends der Angebots-und Nachfragesituation bei mineralischen Rohstoffen. Endbericht im Forschungsprojekt NR, Essen

Gemechu ED, Sonnemann G, Young SB (2015) Geopolitical-related supply risk assessment as a complement to environmental impact assessment: the case of electric vehicles. Int J Life Cycle Assess. doi: 10.1007/s11367-015-0917-4

Gemechu ED, Helbig C, Sonnemann G, Thorenz A, Tuma A (2016) Import-based indicator for the geopolitical supply risk of raw materials in life cycle sustainability assessments. J Ind Ecol 20:154-165

Glöser S, Tercero Espinoza L, Gandenberger C, Faulstich M (2015) Raw material criticality in the context of classical risk assessment. Resour Pol 44:35-46 
Graedel TE, Barr R, Chandler C, Chase T, Choi J, Christoffersen L, Friedlander E, Henly C, Jun C, Nassar NT, Schechner D, Warren S, Yang M, Zhu C (2012) Methodology of metal criticality determination. Environ Sci Technol 46:1063-1070

Guinee J, Gorree M, Heijungs R, Huppes G, Kleijn R, de Koning A, van Oers L, Sleeswijk A, Suh S, Udo de Haes H, de Bruijn H, van Duin R, Huijbregts M (2002) Life cycle assessment - an operational guide to the ISO standards. Kluwer Academic Publishers, Dordrecht

ISO 14044 (2006) Environmental management — life cycle assessmentprinciples and framework. Organization for Standardization

Klinglmaier M, Sala S, Brandao M (2013) Assessing resource depletion in LCA: a review of methods and methodological issues. Int J Life Cycle Assess 19:580-592

Knoeri C, Wäger PA, Stamp A, Althaus H-J, Weil M (2013) Towards a dynamic assessment of raw materials criticality: linking agent-based demand - with material flow supply modelling approaches. Sci Total Environ 461-462:808-812

Mancini L, De Camillis C, Pennington DW (2013) Security of supply and scarcity of raw materials. Towards a methodological framework for sustainability assessment. European Commission, Joint Research Centre, Institute for Environment and Sustainability, Publications Office of the European Union, Luxemburg. doi:10.2788/94926

Mancini L, Sala S, Recchioni M, Benini L, Goralczyk M, Pennington D (2015) Potential of life cycle assessment for supporting the management of critical raw materials. Int J Life Cycle Assess 20:100-116

Maslow AH (1943) A theory of human motivation. Psychol Rev 50:430 437

Melloul AJ, Collin ML (2003) Harmonizing water management and social needs: a necessary condition for sustainable development. The case of Israel's coastal aquifer. J Environ Manag 67:385-394

Morley N, Eatherley D (2008) Material security_ensuring resource availability tor the UK economy. Chester

Nansai K, Nakajima K, Kagawa S, Kondo Y, Shigetomi Y, Suh S (2015) Global mining risk footprint of critical metals necessary for lowcarbon technologies: the case of neodymium, cobalt, and platinum in Japan. Environ Sci Technol 49:2022-2031

Prins AG, Slingerland S, Manders AJG, Lucas PL, Hilderink HBM, Kok MTJ (2011) Scarcity in a sea of plenty? Global resource scarcities and policies in the European Union and the. Netherlands Environmental Assessment Agency PBL, Netherlands

Sala S (2013) Assessing resource depletion in LCA: a review of methods and methodological issues. In: Mancini L, De Camillis C, Pennington D (eds) Security of supply and scarcity of raw materials. Towards a methodological framework for sustainability assessment. European Commission, Joint Research Centre, Institute for Environment and Sustainability, Luxembourg, pp 24-27

Sala S, Vasta A, Mancini L, Dewulf J, Rosenbaum (2015) Social life cycle assessment. State of the art and challenges for product policy support. Luxembourg (Luxembourg): Publications Office of the European Union. ISBN: 978-92-79-54054-7

Schneider L, Berger M, Schüler-Hainsch E, Knöfel S, Ruhland K, Mosig J, Bach V, Finkbeiner M (2014) The economic resource scarcity potential (ESP) for evaluating resource use based on life cycle assessment. Int J Life Cycle Assess 19:601-610

Sonnemann G, Gemechu ED, Adibi N, De Bruille V, Bulle C (2015) From a critical review to a conceptual framework for integrating the criticality of resources into life cycle sustainability assessment. J Clean Prod 94:20-34

Stewart M, Weidema B (2005) A consistent framework for assessing the impacts from resource use. Int J Life Cycle Assess 10:240-247

Tercero Espinoza L (2013) Criticality of mineral raw materials and sustainability assessment. In: Mancini L, De Camillis C, Pennington D (eds) Security of supply and scarcity of raw materials. Towards a methodological framework for sustainability assessment. Joint Research Centre, Institute for Environment and Sustainability, Publications Office of the European Union, Luxemburg, pp 51-52

U.S. Geological Survey (2015) Mineral commodity summaries 2015: U.S. Geological Survey, 196 p., http://dx.doi.org/10.3133/ 70140094

UNEP (2011) Recycling rates of metals. A status report of the International Resource Panel. Available at: http://www.unep.org/ resourcepanel/Portals/24102/PDFs/Metals_Recycling_Rates_ 110412-1.pdf

van Oers L, de Koning A, Guinee J, Huppes G (2002) Abiotic resource depletion in LCA. Amsterdam 